\title{
REALISMO E UTOPIA EM ROBERT MICHELS
}

\author{
Pedro Floriano Ribeiro
}

\begin{abstract}
RESUMO
O artigo aponta e discute as principais influências teóricas e politicas de Robert Michels na construção de Sociologia dos partidos políticos, tentando ir além das fontes mais conhecidas, como Gaetano Mosca, Vilfredo Pareto, Max Weber e Gustave Le Bon. Como Michels não se preocupou em construir definições claras sobre seus conceitos principais, procurou-se extrair a essência de seu raciocínio, apresentando as concepções e influências teóricas predominantes no livro, e destacando as mudanças entre a primeira edição, de 1911, e a segunda, de 1925. Para tanto, realizou-se um estudo das 989 notas explicativas desta segunda edição (além do texto principal em si). Além de discutir as fontes explicitadas no livro, o artigo também esboça uma "análise genética" da obra, levantando alguns fatos biográficos prévios à sua publicação e no intervalo entre as duas edições, e recorrendo, ainda, a outros trabalhos de Michels. Após debater as concepções e críticas do autor sobre democracia, revolução, socialismo, sindicalismo e anarquismo, o artigo termina com um balanço sobre as fragilidades e contribuições da obra de Michels, destacando que a chave para se compreender vida e obra do autor reside em perceber as tensas disjuntivas estabelecidas entre realismo e utopia e entre o Michels militante e o Michels analista.
\end{abstract}

PALAVRAS-CHAVE: Robert Michels; partidos politicos; lei de ferro da oligarquia; organização; biografia.

\section{INTRODUÇÃO}

A mesma afirmação pode ser feita tanto em relação a Robert Michels quanto em relação à sua obra principal, Sociologia dos partidos políticos: ambos são muito mais citados do que conhecidos ou estudados (ou mesmo lidos). Superficialidade e anacronismo são as marcas da maior parte das abordagens e referências a Michels e a seu livro, em geral mais preocupadas em execrar e refutar aprioristicamente suas teses - que vão muito além da lei da oligarquia - do que em conhecê-las com alguma profundidade, na complexidade que várias delas carregam. Se consideramos que seu livro desnuda muitos dos vícios e desvios do movimento socialista, e que o autor trafegou da militância no socialismo revolucionário para a adesão explícita ao fascismo, a explicação para isso talvez esteja no fato de que, como diz Michels (2001, p. 7), "[...] as palpitações excluem o trabalho das ideias".

Um olhar um pouco mais atento sobre sua obra-prima - principalmente em sua segunda edição, de 1925, considerada pelo autor como a versão definitiva - já é capaz de revelar, entre outras coisas, que o raciocínio de Michels é bem mais complexo do que a assertiva "quem diz organização, diz oligarquia"; que sua tese não é monocausal, assentada apenas no fator do tamanho da organização, como critica Panebianco (1995); que o autor não conhecia "apenas" a socialdemocracia alemã, já que faz inúmeras referências sobre os movimentos socialistas da Itália e da França, principalmente, mas também da Áustria, Inglaterra e diversos outros países (inclusive Brasil ${ }^{1}$ ); e que sua análise não se baseia apenas na pinçada de fatos e casos do tempo da militância, mas também na coleta (ainda que não sistemática) de documentos oficiais (atas de congressos, manifestos, resoluções), de declarações de dirigentes na imprensa (principalmente em órgãos socialistas, da Alemanha e Itália), e de fontes secundárias diversas. Esse olhar atento é capaz de revelar, ainda, a erudição de um autor

\footnotetext{
${ }^{1}$ Michels (2001, p. 76-77; 497, nota 11) faz duas referências ao Brasil em seu livro. Na primeira, aponta a ascensão do Marechal Hermes da Fonseca rumo à Presidência da República como exemplo de estratégia política comumente empregada pelos líderes para convencer os liderados a aceitar suas posturas e decisões: os ultimatos e ameaças (às vezes efetivados) de renúncia ao cargo. Na segunda, o autor destaca a origem social burguesa de muitos dos dirigentes do nascente movimento operário brasileiro, a partir de informações (secundárias) sobre a ocupação dos líderes de congresso realizado em São Paulo, em 1902.
}

Rev. Sociol. Polít., Curitiba, v. 20, n. 44, p. 31-46, nov. 2012 
que trafegava (embora nem sempre de modo seguro) pelos cientistas sociais e historiadores de sua época, pelos teóricos marxistas e socialistas de todos os matizes, e também pelos textos, voltados à intervenção política direta, escritos pelos líderes socialistas europeus mais destacados.

Levando em consideração essa complexidade, o objetivo deste artigo é apontar e discutir as principais influências teóricas e políticas de Michels na construção de Sociologia dos partidos políticos, tentando ir além das fontes mais conhecidas, como Mosca, Pareto, Weber e Le Bon. Michels não se preocupou em construir e apresentar definições claras sobre seus conceitos principais, como democracia e oligarquia, que são eivados de ambiguidades e incoerências - principalmente na edição de 1925, que embute as transformações experimentadas por um autor que, no interregno de quatorze anos, passara de um socialista com tendências anarco-sindicalistas para um militante fascista. Assim, procurou-se neste artigo extrair a essência do raciocínio de Michels, apresentando as concepções e influências teóricas predominantes no livro (destacando as mudanças de postura entre as duas edições), e levando sempre em conta que a maioria dos casos comporta mais de uma interpretação.

Para tanto, foram estudadas, além do texto principal em si, as 989 notas explicativas da segunda edição do livro, que revelam muito do raciocínio e das fontes teóricas e empíricas do autor $^{2}$. Como destaca Cook (1971), no entanto,

2 A primeira edição do livro foi publicada em 1911, em alemão. Em algumas traduções dessa primeira edição, publicadas em 1914-1915, Michels já acrescenta dois novos capítulos introdutórios, e cerca de 340 notas de rodapé; é o caso de uma das edições aqui empregadas, norte-americana (MICHELS, 1968). Na segunda edição, de 1925 (publicada em alemão), Michels amplia todos os capítulos e seções, inclui uma figura-resumo de sua tese da oligarquia, e mais um capítulo na Introdução; fundamentais para uma compreensão mais aprofundada da obra, as notas de rodapé passam a ocupar mais de cem páginas. Além disso, Michels aproveita para comentar fatos relativos ao interregno de quatorze anos entre as duas edições, principalmente quanto à atuação dos movimentos socialistas europeus durante e após a I Guerra Mundial; e para responder a algumas das críticas recebidas desde 1911 (vale destacar que a primeira edição disseminou-se com uma velocidade impressionante para a época, sendo logo traduzida para o italiano, francês, inglês e japonês). As edições mais conhecidas no Brasil (MICHELS, 1982; s/d) são traduções resulta praticamente impossível analisar Sociologia sem situá-lo no debate político da época, associando o autor ao militante: não apenas porque a produção acadêmica de Michels acompanha, em grande medida, as transformações políticoideológicas de cunho pessoal operadas ao longo do tempo (numa causalidade recíproca), mas também porque, em relação a muitos temas, as influências políticas (e de amizade) se mostram tão ou mais importantes quanto as teóricas na construção do raciocínio michelsiano. Ou seja: a complexidade, ambiguidade e evolução verificadas nas ideias do Michels acadêmico - não só em seu livro principal, mas ao longo de uma vasta produção com mais de 800 títulos $^{3}$ - são inseparáveis das crenças, decepções e transformações operadas no Michels ativista. Nesse sentido, além de discutir as fontes teóricas explicitadas no livro, o artigo também esboça uma análise genética da obra, levantando alguns fatos biográficos prévios à sua publicação, e no espaço de quatorze anos entre a primeira e a segunda edições, a partir de autores que analisaram de maneira mais detalhada a trajetória de Michels ${ }^{4}$. Além dos dados biográficos, a transformação do pensamento de Michels também é captada por meio da comparação entre edições diferentes do livro, finalizadas em 1911, 1914 e 1925. Certas lacunas foram preenchidas, ainda, recorrendo-se a outras

de versões da primeira edição (não foram traduzidas direto do alemão), sem as notas explicativas e sem os capítulos introdutórios. A edição de 1925 aparece em português apenas em 2001 (MICHELS, 2001), traduzida diretamente do alemão.

3 O levantamento bibliográfico mais completo que conheço sobre a produção de Michels, que lista mais de 800 publicações (agregando e ampliando outros levantamentos prévios), se encontra em Teixeira (2000, p. 219-274). Para uma versão resumida, que inclui apenas os títulos mais relevantes, ver Linz (1998, p. 130-134).

4 Algumas das principais análises sobre a obra de Michels são as de Burnham (1943), Selznick (1943), Cassinelli (1953), Dahl (1958), Sartori (1960; 1994), Lipset (1962; 2003), Roth (1963), May (1965), Cook (1971), Bottomore (1974), Albertoni (1990), Tuccari (1993), Linz (1998) e Leach (2005). O mais bem fundamentado trabalho disponível em português, que trata da obra e vida de Michels, é o de Teixeira (2000). No Brasil, ver Sarti (1996), Couto (2010) e Ribeiro (2012). As informações biográficas foram consultadas principalmente em Cook (1971), Linz (1998) e Teixeira (2000). 
publicações do autor, uma prévia e outra posterior às edições de Sociologia (MICHELS, 1908; 1927).

$\mathrm{O}$ artigo começa discutindo as visões do Michels utópico, sobre democracia, revolução e fascismo. Em seguida, destaca-se o Michels realista, que aponta os limites da democracia liberal, do socialismo, do sindicalismo e do anarquismo, todos fadados a se transformarem em oligarquias. As considerações finais apontam algumas fragilidades e contribuições da obra de Michels, e destacam que a chave para se compreender vida e obra do autor - em toda a complexidade e ambiguidade que carregam - reside em perceber as tensas disjuntivas estabelecidas entre realismo e utopia e entre o Michels militante e o Michels analista.

\section{UTOPIA: DEMOCRACIA, REVOLUÇÃO E FASCISMO}

Michels (2001, p. 56-60, 171-175) entende a democracia enquanto soberania (predomínio) da vontade das massas (vontade geral) nas decisões que afetam a comunidade; iguala, assim, democracia a soberania popular. A partir disso, a democracia ideal é a democracia direta, em que se consegue "[...] alcançar o máximo possível de emanação não mediada da vontade popular no que toca à configuração da vida social[...]" (idem, p. 56). No entanto, admite que razões práticas tornam a democracia direta inviável em grandes agrupamentos, o que acarreta a necessidade da escolha de delegados, "[...] com a incumbência de representar a massa e de facilitar a execução da respectiva vontade" (idem, p. 61); a representação política deve, assim, "[...] manifestar a vontade geral por intermédio da vontade particular" (idem, p. 175). Nessa democracia representativa ideal, os governados controlam os governantes: "[...] a totalidade do povo é responsável pelos que exercem o poder e que estão na dependência desse mesmo povo" (idem, p. 26). O problema é que, a não ser em questões muito específicas e menos complexas, a vontade não é passível de ser transmitida ou representada (por motivos apresentados adiante), o que se constitui em (apenas) um dos fatores que impedem que as massas controlem os líderes.

Como fica claro, essas concepções derivam de Rousseau, um dos autores mais evocados por Michels - que cita uma das passagens mais conhecidas de $O$ contrato social: “[...] à l'instant qu'un peuple se donne des représentants, il n'est plus libre [...]"5 (idem, p. 171). Contudo, notas "histórico-teóricas" acrescentadas à segunda edição (Parte II, cap. 3) explicitam outras influências importantes, como a do socialista utópico francês Victor Considérant (cuja obra possui, também, clara inspiração rousseauniana), e a do alemão Wilhelm Hasbach, autor contemporâneo a Michels que recorre aos federalistas norte-americanos para defender mecanismos de democracia direta ${ }^{6}$. Além dos três (e de Robespierre, também lembrado), Michels (idem, p. 464-465, n. 1-18) escora-se ainda em outros autores, de diferentes correntes teóricas e políticas, para levantar os problemas da representação. Merecem destaque aqui figuras centrais da literatura anarquista, principalmente Proudhon, Bakunin e Malatesta; e uma ampla gama de autores socialistas, como Kautsky, Rosa Luxemburgo e o próprio Marx, que embora encarem a representação parlamentar " [...] como uma das suas armas [...] não deixaram nem deixam de se sentir obrigados a reconhecer ocasionalmente os perigos da delegação de poderes, mesmo quando ela resulta do direito universal ao voto" (idem, p. 174). Reconhecidos por Michels como precursores e mestres, além de amigos pessoais (LINZ, 1998, p. 43-44), Gaetano Mosca e Vilfredo Pareto também embasam a concepção sobre a inocuidade da representação: a partir do momento do voto, os governantes passam a ter o comando sobre as massas, e o discurso da democracia como governo do povo cai em um vazio demagógico (MICHELS, 2001, p. 174) ${ }^{7}$.

\footnotetext{
5 Em francês, no original. " [...] No instante em que um povo dá-se representantes, ele não é mais livre [...]” (nota do revisor).

${ }^{6}$ A obra de Considérant bastante citada por Michels é $L a$ Solution ou le gouvernement direct du peuple (Paris: Phalanstérienne, 1850). A de Wilhelm Hasbach é Die moderne Demokratie. Eine politische Beschreibung (A democracia moderna. Uma descrição política; Jena, 1912).

7 As obras de Mosca e de Pareto a que Michels mais se refere correspondem aos trabalhos mais conhecidos desses autores. De Mosca: Elementi di scienza politica $\left(2^{\mathrm{a}} \mathrm{ed}\right.$, Turim, 1923; a primeira edição, bem menos completa que essa, é de 1896); Sulla teorica dei governi e sul governo parlamentare. Studi storici e sociali (Roma: Loescher, 1884) e Questioni pratiche di diritto costituzionale (Turim, 1898). De Pareto, Michels recorre principalmente a Les Systèmes socialistes (Paris: Giard and Brière, 1892) e a Trattato di Sociologia Generale (Florença, 1916).
} 
Se aquela é a concepção predominante de democracia no livro, em alguns trechos aflora o Michels (idem, p. 37-38, 123) militante socialista, quando a democracia passa a ser associada genericamente à revolução social, única estratégia viável para colocar as massas no comando, fazendo prevalecer a vontade geral. Aqui, a compreensão do raciocínio michelsiano não pode se dar sem levar em conta o debate interno que se processava no Partido Social-Democrata Alemão (SPD) na virada do século dezenove para o vinte, que influenciou sobremaneira a confecção de Sociologia ${ }^{8}$. Membro do partido até 1907 (quando tinha 31 anos), Michels situava-se, do ponto de vista marxista, nas alas mais ortodoxas, opondose firmemente aos revisionistas (idem, p. 250), como Eduard Bernstein (por quem nutria, no entanto, grande admiração e respeito intelectual, sendo bastante citado ao longo do livro). Em relação às estratégias, criticava a prioridade conferida por August Bebel à atuação institucional e parlamentar, e ao fortalecimento da organização partidária, e defendia táticas mais próximas à ação revolucionária direta, assentada na ideia de greve geral de Rosa Luxemburgo - autora bastante citada por Michels no livro, principalmente sua obra principal, Greve de massas, partido e sindicatos (1906). Contra a "degeneração parlamentar" do SPD, Michels aspirava à criação de uma corrente sindicalista radical no partido - o que não ocorreu (COOK, 1971; LINZ, 1998).

A defesa de uma ação política mais direta e voluntarista prenuncia, no militante Michels, as críticas à organização que serão consolidadas em Sociologia. Dirigindo-se claramente a Bebel, Michels (1908) já criticava então "o amor à organização pela organização em si mesma", adiantando aquele que seria um dos motes do livro. Além de Luxemburgo, as fontes desse sindicalismo revolucionário (que Michels posteriormente julgaria inócuo para resolver os problemas acarretados pela representação) situavam-se especialmente nos sindicalistas radicais franceses de corte proudhoniano, como Hubert Lagardelle, Edouard Berth, Émile Pouget e, principalmente, Georges Sorel, com quem Michels manteve as

\footnotetext{
8 Vale destacar que Michels nunca ocupou um lugar de destaque no SPD, seja em termos das atividades organizacionais, seja em relação ao rico debate teórico que então se dava.
}

relações intelectuais mais duradouras ao longo de sua carreira (COOK, 1971) ${ }^{9}$.

Vários pontos de Sociologia (ampliados na segunda edição) evidenciam que a influência marxista (de Marx, mas também de diversos marxistas) nunca desaparecera por completo em Michels. Recorrendo muitas vezes ao Manifesto do Partido Comunista, Michels (2001, p. $267-$ $280,327,409-418)$ interpreta a luta de classes como motor da história, a consciência de classe como seu combustível, e a revolução proletária como única alternativa histórica possível para uma efetiva transformação social, que nunca seria atingida por meio de estratégias reformistas graduais ou de compromissos de classe. Numa arrojada tentativa de articulação entre Mosca, Pareto e Marx, Michels (idem, p. 418) afirma que a tese dos primeiros acerca da inevitabilidade de comando das maiorias pelas minorias não contradiz, mas completa a concepção da história como sucessão de lutas de classes, já que estas vão sempre desembocar " [....] na constituição de uma nova oligarquia que se amalgama com a antiga. A doutrina das "classes políticas" não é contestável pelo marxismo. Porque ela é simplesmente a resultante, não no sentido quantitativo, mas sim em sentido qualitativo, das relações de força que em cada momento procuram encontrar expressão no seio da sociedade" (ibidem).

Não há muito sentido, assim, na afirmação de Linz (1998, p. 50) de que "El verdadero adversario de Michels era Marx [...]", nem na de Cook (1971, p. 775), quando afirma que na essência de Sociologia estava um ataque ao sindicalismo radical. A meu ver, os verdadeiros adversários de Michels eram os dirigentes (não só alemães) que constituíam aristocracias operárias em nome do marxismo, do socialismo, ou da democracia. Sintetizando as posições do ativista que já se afastava (algo amargurado) do $\mathrm{SPD}^{10}$ e redigia

\footnotetext{
9 As principais referências desses autores utilizadas por Michels são: Hubert Lagardelle, Le Parti Socialiste et la Confédération du Travail. Discussion avec J. Guesde (Paris: Rivière, 1907); Edouard Berth, Les nouveaux aspects du socialisme (Paris: Rivière, 1908); Émile Pouget, Le parti du travail (Paris: Bibliothèque Syndicaliste, 1903), e Georges Sorel, Les Illusions du progrès (Paris: M. Rivière, 1908).

10 Michels continuaria como militante socialista nos anos seguintes, mas então no Partido Socialista Italiano, onde
} 
seu Sociologia, o próprio Linz (1998, p. 20) destaca que a pretensão de Michels era, então, articular autores díspares como Sorel, Proudhon, Pareto e Marx em uma teoria da ação política da classe operária.

Desapontado com os rumos da socialdemocracia alemã, e sem conseguir levar adiante essa articulação teórica, na edição de 1925 de Sociologia Michels define revolução de modo mais abstrato, desvelando, de certo modo, parte da autojustificativa intelectual para sua adesão ao fascismo, já em curso. Então, a revolução é destituída de qualquer conteúdo de revolução proletário-sindical, ou de revolução de classes subjugadas, igualando-se assim revolução e contra-revolução, revolucionário e reacionário: "[...] o termo [revolução] apenas contém a ideia de uma viragem completa do fundamental, não precisando de limitar-se a sua aplicação às ações de uma determinada classe, nem a uma certa forma externa do exercício da força. Assim, será revolucionária toda e qualquer classe que, situando-se em baixo ou em cima, usando das armas ou dos caminhos legais ou dos instrumentos econômicos, promove uma transformação radical do estado de coisas vigente" (MICHELS, 2001, p. 28).

Nesse sentido, Michels (idem, p. 28-29) já não vê diferenças essenciais entre a revolução francesa e a Comuna de Paris, de um lado, e o movimento fascista que tomara o poder na Itália em 19221923 , por outro. Uns e outros somente poderiam ser rotulados como revolucionários ou reacionários a partir de "[...] juízos de valor [que] podem de fato constituir um armamento eficaz para alcançar objetivos políticos e [...] morais, mas que, enquanto instrumentos de definição das tendências de desenvolvimento histórico ou mesmo das diferentes concepções do mundo, são manifestamente insuficientes". Sendo assim, convém “[...] evitar tanto quanto possível as

conseguiu contribuir para o fortalecimento de uma corrente sindicalista. Vale esclarecer seu percurso acadêmico: de 1907 a 1914 foi professor na Universidade de Turim; entre 1914 e 1928, lecionou economia na Universidade de Basileia (Suíça); em 1928, graças à intervenção direta de Mussolini, é nomeado para um posto na Universidade de Perugia, onde trabalhou até sua morte (1936), colaborando com o projeto da Facoltà Fascista di Scienze Politiche. Sobre essa trajetória, cf. Teixeira (2000). etiquetas designatórias em matérias tão complexas" (idem, p. 29).

A transformação política operada no plano pessoal se reflete, no livro, em incoerências entre trechos escritos em 1911 e 1925 . A posição do autor sobre o bonapartismo e o cesarismo é um desses casos. Em trecho escrito para a primeira edição, e baseado na obra do próprio Luís Bonaparte (Idées Napoléoniques, publicado em Turim em 1852, mas com primeira edição de 1839), além de análises sobre seu governo (não constando referências ao 18 Brumário, de Marx), Michels (idem, p. 233-234) define o bonapartismo como "[...] a teoria que defende um poder unipessoal originariamente dimanado da vontade comum mas dela emancipado e tornado senhor de si mesmo, o qual encontra na sua origem democrática a defesa para o seu presente antidemocrático. [...] a governação do césar torna-se órgão legítimo da soberania popular. 'Il sera la démocracie personnifiée, la nation faite homme'11. É uma síntese da democracia com o poder pessoal. [...] O bonapartismo não conhece elos intermediários".

Michels prossegue, afirmando que "O banho de limpeza plebiscitário vem dar legitimidade de princípio a toda e qualquer ilegalidade" (idem, $\mathrm{p}$. 255) e conclui que "A concepção bonapartista da soberania popular não é democrática [...]" (idem, p. 488 , n. 9)

Para Michels (2001, p. 255-259; 368-369), os partidos e sindicatos socialistas também eram governados internamente pela lógica plebiscitária bonapartista, que prospera "[...] junto das massas de pendor democrático porque as deixa na ilusão de que continuarão a ser elas a deter o poder sobre quem exerce o poder [...]" (idem, p. 255). Valendose das falas e textos de teóricos e dirigentes socialistas, Michels afirma que os líderes referendados pelas massas veem-se como encarnação da vontade delas, mais autorizados a exigir "[...] obediência e submissão à sua vontade individual do que o dirigente aristocrático que ocupa o seu lugar por nascimento" (p. 256). Baseado em Sorel, coloca que, enquanto a monarquia e a aristocracia se apoiavam em Deus

11 No original, em francês. Tradução livre: "Será a democracia personificada, a nação tornada homem". A citação é de obra do político e jurista francês Édouard Laboulaye: Paris en Amérique (Paris: Charpentier, 1869). 
como fonte de legitimidade - qualquer afronta aos governantes era uma afronta a Deus, - os modernos dirigentes sindicais e partidários se apoiam na legitimidade conferida pelas urnas - e qualquer contestação à sua autoridade equivale a um ataque à democracia tout court. Tem-se, assim, “[...] uma teoria de direito popular que se transformou novamente em teoria de direito divino [...] no qual o direito ao poder decorrente de um plebiscito reclama para si uma força vinculativa permanente" (idem, p. 259).

Essa era a compreensão de Michels sobre a temática em 1911. Em parágrafo acrescentado em 1925 (mas sem eliminar os trechos acima citados), Michels já afirma que "O cesarismo ainda é democracia; pode reclamar-se de o ser porque a sua origem imediata reside na vontade popular" (idem, p. 36; grifo no original). Sob esse ponto de vista, Michels chega mesmo a "absolver", em 1925, os dirigentes da social-democracia alemã fato praticamente ignorado pelos comentadores de sua obra. Para Michels (idem, p. 143), a despeito de métodos autoritários e bonapartistas e da formação de uma aristocracia operária, "[...] os camaradas da direção nunca perderam o contato com as bases, que a tática da direção, com poucas exceções, coincidiu inteiramente com a das massas [...], que a comunhão de ideias entre dirigentes e dirigidos nunca se desfez e que tanto o comitê executivo como o grupo parlamentar [...] representavam de fato a opinião geral dos camaradas espalhados pelo país".

Se sempre haverá líderes e liderados, e se o que importa é apenas e tão somente a correspondência entre as vontades dos dirigentes e das massas, um partido, movimento ou líder carismático que não se preocupam em evocar o rótulo democrático por meio de eleições ou outros mecanismos inócuos, podem ser considerados, em última instância, como democráticos, desde que expressem a vontade geral. É nesse sentido que, em um segundo elemento de sua autojustificativa intelectual, Michels (idem, p. 21) afirma que Mussolini exercia o poder na Itália “"...] com perfeita consciência do seu direito a uma liderança em todos os aspectos essenciais ilimitada de um partido de milhões destinado a exercer a sua dominação: 'Tempo Primo e Secondo'”. Em artigo posterior, Michels (1927, p. 756) corrobora essa sua interpretação quando afirma que Mussolini (com sua "responsabilidade e trabalho assíduo") encarnava não apenas o partido, mas o Estado italiano; já o partido fascista, embora sem aprovação formal da maioria dos italianos, "[...] it fully represents the authentic and autochthonous popular will. From this results the adoption of the consensual theory which rests (more than upon the popular vote) upon a public opinion mensurable less by the liberty of the press than by the number of adherents and political and economico-social organizations. It is to some extent popular enthusiasm which serves the parties of the élite as justification of their acquired rights. [...] An élite, theoretically sure as it is both of its calling and its power, will, by definition, be self-sufficient; there is no need for the élite to have the majority in agreement with it"12 (MICHELS, 1927, p. 771772).

Linz (1998) lembra que, em trabalhos posteriores ao Sociologia, Michels passa a conferir, ainda que timidamente, algum valor ao fator numérico (a maioria) para definir a vontade popular. No entanto, como a citação acima evidencia, isso não foi suficiente para esclarecer a qual vontade popular o autor alemão se refere em sua concepção de democracia. Nos momentos marxistas de Sociologia, Michels (2001, p. $267-$ $280,304)$ toma como índice da vontade popular a preferência do proletariado organizado, e não do eleitorado disperso - embora considerando que seria inexorável o proletariado passar a constituir a maioria do eleitorado votante. Deixado o marxismo de lado, Michels parece se apoiar apenas em uma noção metafísica e rousseauniana de certa "vontade geral", o que recoloca a questão na estaca zero. No trecho transcrito acima essa inconsistência se sobressai, e Michels não vê qualquer problema na não coincidência entre "vontade popular" e "maioria dos italianos". O contorcionismo intelectual de Michels, que parece autojustificar sua adesão ao fascismo, não atingiu

12 “[...] Representa plenamente a vontade popular autêntica e autóctone. Disso resulta a adoção da teoria do consenso que se baseia (mais que no voto popular) em uma opinião pública mensurável menos pela liberdade de imprensa que pelos números de aderentes e de organizações políticas e sócio-econômicas. Em certa medida é o entusiasmo popular que serve aos partidos da elite como justificativa para seus direitos adquiridos. [...] Uma elite, teoricamente segura como é tanto de sua vocação como de seu poder, por definição será auto-suficiente; não há necessidade para a elite de ter a maioria em concordância com ela" (N. R.). 
envergadura suficiente para deixar as coisas $\operatorname{claras}^{13}$

\section{REALISMO: OLIGARQUIA E OLIGARQUI- ZAÇÃO}

$\mathrm{Na}$ acepção michelsiana, é impossível que a democracia autêntica - correspondência da vontade dos liderados com a vontade e as decisões dos líderes, que são controlados por aqueles nasça e se mantenha a partir dos mecanismos da democracia representativa. Em lugar da democracia, da eleição de representantes brotará, gradual e inexoravelmente, uma oligarquia: a organização passa a ser comandada por uma casta de dirigentes cujos interesses, valores e, consequentemente, decisões são crescentemente conservadores e adaptáveis ao ambiente (orientados mais à conservação do poder interno e da organização em si, do que à luta pela causa), afastando-se das preferências dos representados. As lideranças referendadas pelo voto popular, "[...] que a princípio são apenas os órgãos executivos da vontade das massas, tornam-se autônomas emancipando-se das massas" (idem, p. 66), o que produz a "[...] dominação dos representantes sobre os representados" (idem, p. 175; grifos no original). Em um processo de distinção de classe, forma-se na organização uma espécie de aristocracia operária, capaz de permanecer longos períodos de tempo no poder. Em termos mais gerais, a história pode ser lida como uma eterna sucessão entre elites, com a maioria sempre alijada, sendo a oligarquia "[...] a forma pré-determinada da vida humana em formações sociais de maior dimensão[...]" (idem, p. 418; ver também p. 113116, 131-138, 164, 194-201, 403-420).

13 Michels teve uma relação pessoal privilegiada com Mussolini, o que foi importante para sua adesão ao fascismo. Em 1923, o autor envia a Mussolini alguns artigos que havia publicado, bastante favoráveis ao Duce e ao fascismo, que acabara de tomar o poder na Itália. A partir daí, eles trocam uma série de correspondências, culminando em um encontro pessoal no início de 1924. Michels filia-se ao Partido Nacional Fascista em 1923, e com sua volta à Itália em 1928 (diretamente facilitada por Mussolini), passa a atuar como propagandista do regime para além do território italiano, o que lhe vale a alcunha de "embaixador fascista" (TEIXEIRA, 2000, p. 158-166). Segundo Teixeira (idem, p. 162), havia uma forte identificação pessoal entre Michels e Mussolini, já que ambos haviam começado suas trajetórias políticas no socialismo revolucionário, antirreformista e antiparlamentar, frustrando-se em suas aspirações iniciais.
Por caminhos diversos, Michels chega a conclusões semelhantes às de Mosca e Pareto, e admite a influência dos dois autores em sua formulação, reivindicando tacitamente sua filiação a essa "corrente conservadora" - o que justifica, aliás, sua inclusão na tríade fundadora da teoria das elites (GRYNSZPAN, 1999). No entanto, Michels (2001, p. 403-408) vai mais longe para recuperar as origens dessa "lei sociológica" fundamental segundo a qual as minorias sempre comandam as maiorias: entre os autointitulados revolucionários e/ou democratas, como os seguidores de Saint-Simon e Fourier, os anarquistas (Bakunin à frente) e os sindicalistas revolucionários, sempre se encontram, no plano teórico ou prático, afirmações sobre a necessidade de direção das massas. Somente o marxismo teria questionado seriamente a necessidade de uma elite dirigente, já que a supressão das classes levaria à extinção do Estado e, consequentemente, à supressão de qualquer camada dirigente. Entretanto, a passagem dessa formulação do plano teórico para as propostas práticas evidencia que o sistema socialista tampouco escaparia da regra geral sobre a formação de elites dirigentes - o que os primeiros anos da revolução bolchevique já deixavam claro (idem, p. 409-414).

O conceito de oligarquia não é claramente demarcado por Michels em seu livro (CASSINELLI, 1953; DAHL, 1958; COOK, 1971; LEACH, 2005) ${ }^{14}$. A definição extraída acima é a que subjaz, de modo mais ou menos tácito, na maior parte de sua obra, como uma antítese à democracia representativa ideal. A tese de Michels sobre a inexorabilidade da formação de oligarquias é construída de modo absolutamente assistemático, sem uma metodologia de análise minimamente rigorosa. Ele baseia-se, sobretudo, em material de diversos órgãos da imprensa socialista europeia, em relatos de autores socialistas (em livros, jornais, revistas etc.) e na observação in loco, por meio da qual seleciona casos

14 Ao longo do livro, Michels entende a oligarquia ora como um sistema de decisões oposto à democracia, ora como um grupo de líderes (oligarcas) que decide sem levar em conta a vontade das massas. No entanto, como aponta Cassinelli (1953), considerando as preocupações de Michels, e os mecanismos causais envolvidos no processo de oligarquização, faz mais sentido tomar como predominante (e mais relevante) o primeiro significado. 
ilustrativos com os quais tivera contato diretamente. No entanto, se a oligarquia e seu sentido de necessidade histórica carecem de exatidão e fundamentação no pensamento michelsiano, as variáveis causais que afastam a democracia representativa de seu ponto ideal, conduzindo-a a uma situação oligárquica, são bem mais claras e teoricamente mais consistentes. Trata-se, basicamente, de duas ordens de fatores.

Em primeiro lugar, há os fatores de ordem psicológica, que afetam as massas e os dirigentes. Michels parte da premissa de que a maior parte dos indivíduos é apática, passiva e indiferente em relação à política; além disso, os homens tendem a ter sua capacidade intelectual e sua racionalidade crítica suprimidas quando reunidos em uma multidão. As massas, naturalmente incompetentes, sugestionáveis e irracionais, incapazes de decidir sobre as questões coletivas que lhes interessam, não só aceitam como desejam que alguém assuma o comando ${ }^{15}$. Esses comandantes serão os líderes mais habilidosos, carismáticos (Michels emprega o termo, mas sem precisão weberiana), dotados de atributos de personalidade superiores (liderança, inteligência, oratória etc.), que serão mais e mais potencializados com o próprio exercício do poder, aumentando o fosso entre liderados e dirigentes que se tornam indispensáveis perante os olhos daqueles, e para si mesmos. Os dirigentes, em um processo de ascensão social, se destacam da classe e das atividades originárias, passando a cultivar valores, interesses e atitudes cada vez mais diferentes em relação à vontade daqueles a quem deveriam representar (processo de aburguesamento). Como dependem de seus cargos para manter a nova condição social (e graças também à sede "natural" pelo poder), a organização se transforma de instrumento em busca da causa para um fim em si mesmo. A revolução, o socialismo, ou outra modificação radical do status quo, na medida em que colocam em risco sua posição privilegiada, deixam de ser interessantes para esses dirigentes; como são eles que determinam o comportamento e o perfil da organização, o conservadorismo da elite passa a ser o conservadorismo organizacional, com estratégias adaptativas ao ambiente (voltadas à sobrevivência e forta-

\footnotetext{
15 O caráter irracional e altamente sugestionável das massas, aliás, é outro fator que inviabiliza a democracia direta (MICHELS, 2001, p. 58-59).
}

lecimento da organização) substituindo posturas radicais de enfrentamento - principalmente se a organização estiver inserida em um sistema eleitoral competitivo (MICHELS, 2001, p. 75-124, 305315, 334-355, 397-400, 420).

Para a construção dessa vertente psicológica do processo de oligarquização, Michels se apoia sobretudo na literatura de psicologia social, muito em voga à época - especialmente o livro de Gustav Le Bon, Psicologia das multidões (de 1895), mas também em Gabriel Tarde ${ }^{16}$. Faz também referências a Mosca, Pareto, ao sociólogo alemão Werner Sombart (com várias obras citadas ao longo do livro), e a autores socialistas que, influenciados pela teoria leninista, apontavam a incapacidade das massas como principal justificativa para a construção de um partido de vanguarda. Michels recorre, ainda, a autores liberais como Tocqueville, para reforçar a tese sobre o perigo representado pela multidão ${ }^{17}$.

Se há um destaque praticamente unânime, entre os comentadores de Michels, acerca dos fatores psicológicos que afetam as massas, a tese do aburguesamento dos dirigentes, ponto a meu ver bastante importante nessa ordem psicológica de causas, em geral não recebe a devida atenção. Para defender essa ideia de aburguesamento, Michels se sustenta em inúmeros autores socialistas, com suas críticas ao comportamento das direções e aos rumos reformistas e acomodados à ordem que os movimentos socialistas tomavam em muitos países da Europa; refere-se com frequência, também, a um trabalho específico do historiador e político socialista italiano Ettore Ciccotti, sobre a psicologia do movimento operário (Psicologia del movimento socialista - Bari, 1903). Além dessas fontes, ecoam na construção michelsiana as influências de Sorel, Kaustky e, principalmente, as denúncias de Rosa Luxemburgo sobre o

16 De Gabriel Tarde, Michels cita, entre outros, Les crimes des foules (Lyon, 1892).

17 Com um contato indireto com os federalistas norteamericanos (por meio de Wilhelm Hasbach, citado acima), Michels (2001, p. 33-34, 56-57) refere-se a esses autores (além da Democracia na América, de Tocqueville) para demonstrar que também os liberais tinham consciência do perigo representado pelas massas; faz isso de maneira bastante primária e genérica, no entanto, de modo que não se pode dizer que essa literatura tenha sido uma importante fonte teórica. 
burocratismo que acometia as direções dos partidos e sindicatos operários (MICHELS, 2001, p. 442 , n. $24 ; 467-468$, n. 28,33 ). Em passagem que resume sua visão sobre o processo de aburguesamento, Michels (idem, p. 336) afirma que os dirigentes "Adaptam-se às relações vigentes ou, mais ainda, conciliam-se com elas. O que é que lhes interessa o dogma da revolução social? Já fizeram a sua revolução pessoal. No fundo, inconscientemente, os seus pensamentos concentram-se numa só esperança: que continue a existir por longos e bons anos um proletariado que continue a delegar neles as suas atribuições e que os mantenha. Eis porque tais indivíduos criam um novo princípio, o de que a tarefa essencial é organizar mais e mais, até o infinito, e de que a causa do operariado só estará ganha quando o último operário tiver entrado na organização".

A transformação psicológica dos dirigentes é mais acentuada e prejudicial ao movimento (em termos do conservadorismo) quando a origem social desses líderes é baixa, ou seja: quando operários usam a organização como "máquina de ascensão social" (idem, p. 305-315, 341). Nesse sentido, Michels (idem, p. 370-376, 416-417) vê uma chance ligeiramente maior de manutenção dos vínculos de representação (correspondência entre as vontades) quando os dirigentes socialistas são desertores da burguesia (como a maioria dos intelectuais) - desde que se submetam a um processo de proletarização, que crie e mantenha, nesses ex-burgueses, uma nova identidade de classe.

Ao contrário do que a citação acima sugere, a tese sobre a transformação social e psicológica dos líderes não embute uma condenação moral desses dirigentes. Em vários trechos do livro, Michels (idem, p. 262, 343-346, 476, n. 87) ressalta que não é o egoísmo que move o dirigente ou funcionário, nem a busca pelo poder, enriquecimento ou status pessoal, mas sim a mais sincera convicção de que seu trabalho é indispensável à causa coletiva (na qual ele de fato tem fé): ao cumprir com dedicação sua função, a transformação inevitavelmente acontece. Assim, Michels pontua que uma boa burocracia é mais perigosa do que uma má, já que geralmente “[...] o mais autocrata é precisamente o funcionário mais cumpridor das suas obrigações[...]" (idem, p. 262). O único julgamento moral feito por Michels (idem, p. 519-521, n. 46) toca na questão da corrupção dos dirigentes, que avalia como uma exceção.
Nesse sentido, critica a complacência de muitos partidos e sindicatos socialistas em relação ao dirigente que recorre a práticas corruptas em prol da causa e da organização (o fortalecimento do caixa, por exemplo), sem auferir ganhos pessoais; como os atos ilícitos podem sepultar sua carreira política pessoal, uma aura de sacrifício heroico ainda envolve esses líderes. Para Michels, a adoção dessa moralidade de fins abriria as portas para uma corrupção generalizada, com o "corrupto honesto" sendo rapidamente seguido por "corruptos desonestos".

Além das causas de ordem psicológica, o processo de oligarquização decorre de causas técnico-administrativas - que são as mais importantes e generalizáveis da tese michelsiana (CASSINELLI, 1953, p. 782; LINZ, 1998, p. 6870; MICHELS, 2001, p. 243). Aqui, a cadeia argumentativa de Michels inicia-se com o crescimento da organização: a partir de certa quantidade de membros (que Michels não precisa), as decisões não podem mais, por razões práticas, ser tomadas sempre em assembleia geral, o que torna a representação inelutável; além disso, as atividades vão se tornando mais complexas e numerosas, demandando a divisão e a especialização do trabalho, e a remuneração dos dirigentes, profissionalizados para atuarem exclusivamente na organização. A dedicação exclusiva e a especialização na função, por sua vez, aumentam a importância dos dirigentes e funcionários (e sua estabilidade nos cargos), principalmente pela aquisição de conhecimento técnico. Sem esse conhecimento técnico e sem a formação dessa burocracia profissional estável (com cargos e jurisdições bem delimitados, hierarquia de comando, treinamento técnico etc.), a organização de massas não consegue perseguir com o mínimo de eficácia seus objetivos (MICHELS, 2001, p. 53-74, 111-124, 420).

Esse encadeamento causal segue claramente as pegadas da sociologia da burocracia de Max Weber - que foi, talvez ao lado de Sorel, a principal influência ao mesmo tempo pessoal e teórica sobre Michels. Em 1906, Weber convida o jovem Michels para colaborar com a prestigiosa revista Archiv für Sozialwissenschaft und Sozialpolitik, que comandava como um dos editores. Isso não foi suficiente, no entanto, para que Michels superasse as restrições colocadas a seu nome, em virtude da militância no SPD, para assumir postos acadêmicos na Alemanha - restrições que 
provocaram uma manifestação pública de repúdio por parte de Weber, e que acabaram levando Michels à Universidade de Turim. A saída do SPD em 1907, e a passagem do Michels militante, que publicava textos de pequeno fôlego em órgãos socialistas, para o Michels acadêmico, publicando em periódicos científicos de destaque, têm estreita ligação com esse convite e com a aproximação pessoal com Weber, a quem Michels passa a tomar como mestre. Após esses anos de contato, Michels dedicaria a primeira edição de seu Sociologia (somente a primeira) ao "[...] querido amigo Max Weber, el sabio de Heidelberg, quien, en interés de la ciencia, no vacila ante la vivisección, con los saludos de quien tiene un alma gemela a la suya" (LINZ, 1998, p. 16). Em 1913, Weber convida Michels a assumir como diretor adjunto do Archiv, cargo que ocupa até 1915, quando a amizade entre os dois é rompida devido a posições divergentes frente à I Guerra Mundial - com Michels defendendo as decisões italianas e condenando a Alemanha como potência agressora (COOK, 1971; TUCCARI, 1993; TEIXEIRA, 2000).

Antes da publicação de Sociologia dos partidos políticos, Weber já havia publicado, em textos curtos, o essencial de sua sociologia da burocracia, a ideia de que a organização converte$\mathrm{se}$, aos olhos dos dirigentes e funcionários, em um fim em si mesmo, e a tese sobre a tendência de transformação dos partidos e sindicatos de massas em máquinas burocratizadas, crescentemente conservadoras (como seus líderes). Além disso, correspondências trocadas entre os dois deixam evidente que Michels conhecia tais ideias, e que elas foram centrais em sua formulação teórica (COOK, 1971; TUCCARI, 1993; LINZ, $1998)^{18}$. No entanto, não se contam nem dez citações a Weber entre as quase mil notas explicativas do livro de Michels (muito menos do que diversos outros autores de menor importância), o que talvez se explique pelo rompimento da amizade entre eles. Além de Weber,

\footnotetext{
18 Embora Weber tenha se referido com termos bastante próximos, nas obras em que publica tais ideias de modo sistemático - A política como vocação, de 1919, e principalmente Economia e sociedade, de 1921, - a muitas das questões levantadas por Michels em Sociologia, somente uma confusão de datas poderia levar o analista a suspeitar de uma influência recíproca e de peso semelhante entre ambos.
}

Michels não dá o devido crédito a outro autor que, desde 1889, publicava ideias semelhantes sobre a transformação das organizações de massa em máquinas militarizadas e burocratizadas, com dirigentes autônomos frente aos representados: Moisei Ostrogorski, que teria suas teses sistematizadas em A democracia e a organização dos partidos políticos (1902), citada apenas de passagem por Michels. Confrontado com tal lacuna, Michels se defende afirmando que não conhecia o texto em 1911, e que o foco de Ostrogorski era voltado à análise mais dos sistemas políticos dos Estados Unidos e da Inglaterra, e não do funcionamento interno das organizações (LINZ, 1998, p. 45-46). Por fim, também constituem fontes importantes da construção michelsiana sobre as causas técnicas da oligarquização os alertas de Rosa Luxemburgo acerca dos perigos da especialização burocrática (que beneficiam os líderes, em prejuízo das massas e da democracia interna); e a obra do liberal britânico James Bryce, Modern Democracies (de 1921), a que Michels se refere diversas vezes.

Para Michels (2001, p. 37), toda organização social orientada para um fim específico está submetida a esses dois conjuntos de causas, técnicas e psicológicas; irá, assim, se transformar em uma oligarquia. No entanto, como sublinham diversos comentadores (CASSINELLI, 1953; DAHL, 1958; LINZ, 1998; LIPSET, 2003), o foco do autor (e uma de suas maiores contribuições) consiste em mostrar como organizações formalmente democráticas (partidos, sindicatos, associações, movimentos sociais etc.), com eleição periódica dos dirigentes, realização de assembleias, necessidade de prestação de contas etc., tendem a se transformar em oligarquias. Colocando o problema em termos contemporâneos, a preocupação de Michels é demonstrar que os mecanismos de accountability vertical (prestação de contas e eleições) não são capazes de gerar (ou manter) a responsividade dos governantes perante os governados (entendida como a inclinação daqueles em decidir de acordo com a vontade destes) (cf. PRZEWORSKI, STOKES \& MANIN, 1999). Michels (2001, p. 224) admite que os mecanismos eleitorais incentivam os dirigentes a manterem algum contato, ao menos aparente, com as aspirações das massas, sob o risco de perderem espaço para elites internas concorrentes. No entanto, as lideranças conseguem minimizar esse risco, minando o potencial de 
controle dos mecanismos eleitorais, por meio de duas estratégias principais. De um lado, manipulam facilmente as preferências das massas, moldandoas às suas preferências; de outro, levam a cabo estratégias de cooptação dos desafiantes internos, atraídos ao círculo dirigente sempre que possam representar alguma ameaça à elite hegemônica gerando um processo que Michels (idem, p. 233240, 404), referindo-se a Pareto, julga mais apropriado nomear como "amálgama" de elites, em vez de circulação.

Tampouco poderiam garantir a responsividade mecanismos mais agressivos de controle sobre os representantes - como o mandato imperativo, condenado por Michels, ou a realização de referendos e plebiscitos, que poderiam ser uma saída apenas se a massa tivesse mais educação e informação política; caso contrário, convertemse em instrumentos de apoio ao bonapartismo. Por outro lado, se Michels se vale das críticas dos sindicalistas revolucionários e dos anarquistas para apontar as mazelas do sistema representativo, em capítulos finais de Sociologia deixa claro que já não acreditava mais (comparado ao Michels militante) nas medidas profiláticas apontadas pelas duas correntes. Voltando suas baterias aos mesmos autores em que se apoia para criticar a democracia liberal (Sorel, Bakunin, Lagardelle etc.), Michels afirma que nem o sindicalismo revolucionário nem o anarquismo prescindem totalmente, ao passar da teoria à ação (ou ao menos à elaboração de propostas práticas), de mecanismos de delegação de poderes, de constituição de líderes, de formação de uma organização; mecanismos esses que já trazem em si os germes da inevitável oligarquização (idem, parte V, cap. 1, 3-4).

Seria o socialismo o único caminho para se evitar a formação de oligarquias? Embora o marxismo floresça em muitos trechos de seu livro, já na primeira edição Michels (idem, p. 240, 410$419,424-425)$ desconfiava da ditadura do proletariado como via ao socialismo, e não alimentava muitas esperanças em relação à possibilidade da construção deste, sublinhando se tratar de um beco sem saída: não há como fazer a revolução sem um comando forte de revolucionários, que são, no entanto, os reacionários de amanhã, uma nova minoria de oligarcas. Conceber dirigentes socialistas que não se transformam em oligarcas equivale a considerar a possiblidade de transformação do homem em deus, um superdirigente não submetido às pressões psicológicas e técnico-burocráticas que influenciam o comportamento dos líderes. Por outro lado, recorrendo à Kropotkin, Michels (idem, p. 412) afirma que advogar a ditadura em nome da construção da democracia "[...] é o mesmo que proclamar a guerra como arma mais eficaz para a obtenção da paz ou querer utilizar o álcool para combater o alcoolismo. É previsível que um grupo uma vez chegado à situação de detentor dos instrumentos de poder de uma coletividade procure assegurar a manutenção desse poder".

Michels (idem, p. 413-415) localiza as inconsistências da proposta socialista no campo teórico. Para ele (seguindo as pegadas de Sorel), os marxistas teriam ótimas doutrinas econômicas, históricas e filosóficas, capazes de diagnosticar as mazelas da sociedade; no entanto, falham completamente na compreensão das dimensões psicológica e jurídica da democracia e do socialismo. No foco do problema está a liberdade individual, ou a relação entre indivíduo e coletividade, que os teóricos marxistas não conseguem equacionar, caindo ora no anarquismo individual, ora na completa submissão do indivíduo como escravo da massa. Citando o sociólogo austríaco Rudolf Goldscheid (Grundlinien zu einer Kritik der Willenskraft (Linhas fundamentais de uma crítica da força da vontade). Viena: W. Braumüller, 1905), Michels levanta a questão da defesa da personalidade: "[...] se o movimento socialista não refletir sobre o problema da iniciativa individual, ao mesmo tempo na perspectiva da teoria do conhecimento e de uma teoria da vontade, corre o risco de [...] falhar por falta de compreensão da importância do problema da liberdade para o desenvolvimento superior da nossa espécie [...]" (MICHELS, 2001, p. 414).

Em outro trecho, Michels recorre a Simmel (Über soziale Differenzierung. Soziologische und psychologische Untersuchungen (Sobre a diferenciação social. Investigações sociológicas e psicológicas). Leipzig, 1890) para recusar o superdeterminismo marxista, afirmando que o indivíduo não é um simples "peão do jogo econômico": "A sua vida é uma luta constante entre dois campos, de um lado as suas necessidades economicamente determinadas, [...] do outro "a carne e o sangue" que fazem dele o indivíduo que é, que estão "acima" do seu estatuto de classe [...] e que nele podem despertar paixões capazes de o afastarem de seu caminho econômico natural [...]" (MICHELS, 2001, p. 277-278). 
Assim, seja pela dimensão psicológicoindividual (que afeta líderes e liderados), seja pelos aspectos organizacionais (que levarão ao crescente conservadorismo da burocracia estatal socialista), ou mesmo pela improbabilidade de que uma ditadura do proletariado seja realmente transitória, o fato é que "[...] os socialistas podem de fato triunfar, mas não o socialismo, o qual no momento do triunfo cai às mãos dos seus apóstolos" (idem, p. 419).

\section{CONSIDERAÇÕES FINAIS: UTOPIA E} REALISMO EM MICHELS

A análise mais atenta de Sociologia dos partidos políticos revela um autor inquieto, incapaz de se filiar claramente a uma determinada corrente teórica, ou de seguir do início ao fim da obra numa mesma trajetória metodológica ou analítica. $\mathrm{O}$ livro, em 1911, já carregava diversas ambiguidades e inconsistências oriundas dessa inquietação; com sua ampliação em 1925, sem a supressão dos trechos escritos anteriormente, ou nem ao menos com a articulação entre os diferentes momentos, a obra ganha ainda mais ambiguidades, incoerências e paradoxos, transformando-se em algo bem mais complexo. Uma das leituras possíveis de Sociologia, que se procurou adotar neste artigo, é a que o encara como reflexo de uma personalidade complexa, de um autor que tateava no mundo dos fatos em busca de uma democracia idealizada: ambas, utopia e decepção realista, se manifestam na obra e na vida de Robert Michels.

Apesar de sua importância indelével, fica claro que a obra de Michels carrega diversas inconsistências e fragilidades metodológicas e teórico-analíticas. Para ficar apenas nas principais, pode-se destacar que o autor simplesmente desconsidera os fatores ambientais, como variáveis que podem influenciar na oligarquização ou não de uma determinada organização (ROTH, 1963; SARTI, 1996). O internismo da análise - que deixa de lado, por exemplo, os fatores institucionais, a conjuntura política, a competição e a cooperação com outras organizações - foi uma opção consciente de Michels, já que, como destacam Roth (1963) e Linz (1998), em textos anteriores o autor levara em conta aspectos conjunturais na análise do movimento socialista alemão. A opção também fica clara quando, ao resumir sua tese em alguns prefácios redigidos para a primeira edição de Sociologia19, Michels (2001, p. 8-9) destaca que a tendência à oligarquização resultava da conjunção entre fatores ligados à natureza humana, à organização e à "essência da luta política". Essa lembrança sobre a competição política é colocada apenas de passagem ao longo do livro, sendo totalmente suprimida, por exemplo, no esquema gráfico que resume a tese do autor (idem, p. 420). As únicas concessões feitas por Michels a aspectos externos à organização dizem respeito principalmente a diferenças nacionais, referindo-se genericamente a "tradições históricas", fatores ligados a "raça", caráter nacional, hábitos do povo etc. (idem, p. 103, 167, 342-346, 384).

Além do desprezo aos fatores externos, outra crítica logo recebida por Michels tocava na pretensão generalizante e de inexorabilidade histórica de uma análise realizada de modo assistemático, a partir de poucos casos, e sem uma fundamentação metodológica mínima (mesmo para a época). Weber, por exemplo, logo deixou claras essas inconsistências para Michels (TUCCARI, 1993; LINZ, 1998), que tentaria responder (sem muito êxito) na edição de 1925. Em relação à ambição generalizante e ao caráter superdeterminista de uma "lei" sociológica, Michels aparentemente tenta remediar a situação alterando um dos trechos mais conhecidos de sua obra - sem mudar, no entanto, a perspectiva geral que subjaz em praticamente todo o livro. Na edição de 1911, Michels (1982, p. 238) afirma peremptoriamente que "[...] a organização é a fonte de onde nasce a dominação dos eleitos sobre os eleitores, dos mandatários sobre os mandantes, dos delegados sobre os que os delegam. Quem diz organização, diz oligarquia”. Em 1925, a última frase desaparece (MICHELS, 2001, p. 422) e a afirmação ganha uma nova roupagem, menos peremptória, em outro ponto: "Quem diz organização, diz tendência para a oligarquia" (idem, p. 54; grifos no original $)^{20}$.

\footnotetext{
19 Refiro-me aqui aos prefácios redigidos por Michels à primeira edição inglesa, de 1915, e à primeira edição alemã, de 1911, sendo que este é reproduzido em Michels (2001), mas não nas outras edições em português (MICHELS, s/d; 1982).

20 Não se trata, portanto, de um problema apenas de tradução do original alemão, como sugere Cook (1971, p.
} 787). 
Por outro lado, as explicações calcadas em aspectos psicológicos de líderes e liderados tampouco convencem. Mesmo se aceitamos a apatia e a irracionalidade como atributos inerentes às massas (o que não é indiscutível), é de se questionar se um conjunto de eleitores, votando individualmente, também conforma uma multidão - como é o entendimento de Michels, Pareto e Mosca (GRYNSZPAN, 1999). De qualquer modo, se tais assertivas eram aceitas na psicologia social e mesmo entre muitos cientistas sociais do início do século vinte, as afirmações de Michels sobre a superioridade intelectual e a maior inclinação ao exercício democrático do poder por parte dos dirigentes oriundos da burguesia, em comparação aos provenientes do operariado, não possui qualquer sustentação teórica ou empírica; um certo preconceito de classe, que exala ao longo de muitos dos trabalhos dos teóricos elitistas, parece ser a única base de afirmações do gênero. Por fim, Michels não atenta para o fato de que um processo de articulação, e não de substituição, pode se dar entre os objetivos oficiais da organização (socialismo etc.), ainda que progressivamente suavizados, e os objetivos conservadores de adaptação ao ambiente, sobrevivência da organização, manutenção do poder interno etc. Como sublinha Panebianco (1995, p. 38, 51-52), sem essa articulação - que deve ser minimamente efetiva, e não aparente, sob o risco de ser desmascarada após algum tempo -, dificilmente as elites internas se mantêm no controle.

Claramente, Michels não está no mesmo patamar científico e intelectual de contemporâneos seus, como Mosca, Pareto, Weber ou Sorel. Entretanto, fragilidades como as variáveis psicológicas de explicação, a falta de contextualização, ou a pretensão generalizadora e de inexorabilidade histórica de sua tese da oligarquia não devem apagar sua contribuição ao debate sobre a democracia. Como destacam Cassinelli (1953), Cook (1971) e Lipset (2003), Michels contribuiu bastante ao apontar as vantagens (para os dirigentes) e as desvantagens (para os liderados) da especialização burocrática, as tendências de insulamento diretivo e centralização do poder (inclusive nos sistemas socialistas), com o afastamento entre representantes e representados (inclusive em termos de valores e interesses), ou o caráter crescentemente adaptável e conservador dos governantes. Em suma, "[...] Michels pode muito bem ter uma lei de ferro da burocracia, mas apenas uma 'lei de bronze' (de modo algum revestida de ferro) da oligarquia" (SARTORI, 1994, p. 205; grifos no original).

O caráter antidemocrático dos teóricos elitistas sempre levantou acesas discussões (BURNHAM, 1943; BOTTOMORE, 1974; GRYNSZPAN, 1999). O quão antidemocrático era Michels? Se as referências são em relação aos mecanismos da democracia representativa liberal, pode-se afirmar com segurança que Michels foi sempre antidemocrático. Quando jovem, era um antidemocrático à esquerda, defendendo a revolução social e ação direta das massas; depois, converte-se em um antidemocrático à direita, aderindo a um regime abertamente autoritário e violento. Como uma constante do Michels jovem e maduro, ativista e acadêmico, socialista e fascista, tem-se o desprezo por mecanismos como eleições regulares, separação de poderes, pesos e contrapesos institucionais etc. Para Cook (1971), essa aversão reflete a defesa de um sindicalismo radical, que Michels nunca teria abandonado. Entretanto, as duras críticas feitas por Michels (2001, p. 377-385) ao sindicalismo, e o ceticismo demonstrado em relação a sua viabilidade como estratégia para se atingir a real democracia, indicam que essa ilusão já não o movia mais. A meu ver, mais que um democrata frustrado que se converte em antidemocrata, ou um socialista que se torna antissocialista, o que se sobressai, permanecendo sempre, é um Michels revolucionário e voluntarista (anti-organização), que oscila de um ponto a outro contra mecanismos que, julga, apenas falseiam a "verdadeira" democracia. É nessa chave que se compreende sua afirmação taxativa: "Revoluções existiram; democracias, não" (idem, p. 45).

$\mathrm{Na}$ concepção do que seria essa verdadeira democracia se encontra a base da decepção michelsiana: uma concepção rousseauniana em que as preferências e decisões dos representantes correspondem exatamente à vontade dos representados. Assim, quando leitores contemporâneos se valem das afirmações de Michels sobre a impossibilidade crônica da democracia para rotulá-lo de antidemocrático, nada mais fazem do que incorrer em um erro de interpretação: um e outros, quando se referem à democracia, estão pensando em termos absolutamente distintos. A postura de Michels contrária à democracia liberal decorre de sua fé na democracia rousseauniana; vendo a dificuldade 
de se atingi-la, dá o veredito de que esta democracia (não a liberal) é, na verdade, impossível.

Essa acepção de democracia, que orienta seu livro principal, vários outros de seus trabalhos (TEIXEIRA, 2000), e sua trajetória política pessoal, traz implícita desde o início a possibilidade de construção de democracias "verdadeiras" sem eleições, sem respeito às minorias e às liberdades individuais, sem equilíbrio de poderes etc. Nesse sentido, sublinha Bobbio (1995) que os extremismos de esquerda e de direita estão mais próximos entre si do que seus apóstolos admitem, não sendo difícil encontrar exemplos de migrações pessoais do tipo; as díades esquerda-direita e moderação-extremismo não são, assim, coincidentes 21 .

Como argumenta Linz (1998, p. 110), certos erros intelectuais, ainda que cometidos de boa-fé, podem conduzir a escolhas políticas equivocadas. Michels não vê saída: a formação de uma camada de dirigentes, sejam representantes em um sistema democrático liberal, líderes de uma greve geral revolucionária, delegados em uma federação anarquista de barricadas, ou comandantes da ditadura do proletariado ou de um Estado socialista, significa o início do fim da democracia, na medida em que afasta inevitavelmente as decisões políticas da vontade popular. Assim sendo, um partido e um líder abertamente autoritários, mas que encarnam a vontade do povo, não podem ser piores. Nesse sentido, Sartori (1994, p. 72-74) vai ao ponto quando afirma que o realismo político de Michels (e de Mosca e Pareto) deve ser separado de suas opções pessoais antidemocráticas, ou da antidemocracia que transparece em sua obra. A interpretação realista da política feita por Michels contribuiu para a teoria da democracia, sendo passível, ainda hoje, de discussão, interpretação e testes de hipótese; sua antidemocracia, no entanto, não deriva automaticamente desse realismo consistente, mas sim da soma de um "mau realismo" (ao interpretar a democracia existente e o fascismo) com uma idealização (rousseauniana) também equivocada

\footnotetext{
21 Quanto a isso, não deixam de soar irônicas as fontes mais comuns das críticas feitas à antidemocracia de Michels (e de outros elitistas): teóricos e adeptos de diferentes matizes da esquerda radical, que rejeitam os mesmos mecanismos que Michels sempre desprezou.
}

sobre os significados e possibilidades da democracia.

Acrescentaria outros dois erros intelectuais (de "má" interpretação da realidade) que ajudaram a conduzir Michels ao fascismo (erros não cometidos por Mosca, por exemplo). Em primeiro lugar, Michels releva, em nome da sintonia de opiniões entre a vontade popular do povo italiano e o Duce, o caráter claramente totalitário, violento e supressor das individualidades assumido pelo movimento fascista desde o início. Os argumentos sobre liberdade, personalidade e iniciativa individuais, esgrimidos por Michels (2001, p. 414) contra a ideia da ditadura do proletariado, simplesmente desaparecem quando de sua adesão ao fascismo.

Em segundo lugar, Michels assume, sem grande discussão, que organizações oligarquizadas levam inevitavelmente a um Estado oligárquico. Em dado ponto do livro, Michels (idem, p. 393 394) admite que mesmo organizações conduzidas de modo oligárquico podem pressionar a camada dirigente do Estado a rever suas políticas, em benefício das massas representadas por tais organizações; no entanto, esse potencial tende a ser sufocado na medida em que tais organizações forem atraídas pelas forças dominantes - o que acontece cedo ou tarde, dada a adaptabilidade e a sede de poder dos dirigentes de toda organização. Apesar dessa ressalva, de modo geral Michels considera que a impossibilidade da democracia no nível micro significa, em última instância, a inviabilidade da democracia no nível macro. A competição eleitoral no nível do Estado serviria apenas para imprimir maior velocidade ao processo de acomodação conservadora dos partidos inclusive com revisões teóricas, caso necessárias para a vitória eleitoral (como o revisionismo da socialdemocracia alemã).

O que Michels não vê, no entanto, é que a competição entre oligarquias pode produzir um resultado democrático na sociedade. Sem fugir à definição michelsiana de democracia, é de se esperar que os mecanismos eleitorais incentivem os líderes das oligarquias a adotarem as posturas desejadas pela maior parte do eleitorado, de modo a vencer a competição contra as demais oligarquias; tem-se, assim, a responsividade almejada por Michels, como subproduto da accountability eleitoral (SARTORI, 1994; LIPSET, 2003). Tal crítica pode exalar certo anacronismo, 
considerando se tratar de um autor préschumpeteriano (COOK, 1971); mas não totalmente, já que Michels capta a possibilidade desse deslocamento dos laços de responsividade, da base partidária organizada para o eleitorado disperso, conforme os líderes do partido se inserissem no jogo eleitoral. Qual vontade eles deveriam expressar? Embora deixe margens para dúvidas, em geral Michels condena a "[...] desobrigação dos dirigentes em relação às limitações impostas pela massa organizada, na medida em que as substitui por um laço mais elástico com a massa amorfa dos votantes" (MICHELS, 2001, p. 77; cf. também p. 176-180, 237-238).

Com essa condenação, Michels fecha qualquer possibilidade de efetivação da sua democracia rousseauniana em um Estado nacional. A conclusão central de Sociologia dos partidos politicos é bastante pessimista: a democracia, enquanto capacidade de concretização efetiva da vontade popular nas decisões coletivas, é um fenômeno irrealizável. Além de Rousseau, Michels (idem, p. 421) evoca, nas páginas finais do livro, Mosca e
Pareto para afirmar que, em última instância, continua válido o princípio segundo o qual a maioria é sempre governada por uma minoria reduzida. No entanto, centelhas de otimismo também despontam ali, quando afirma (a partir de Rousseau e Considérant) que a educação política das massas pode aliviar as tendências à oligarquização, ao fornecer instrumentos para um controle mais efetivo sobre os representantes (idem, p. 427-428), e quando sustenta que, ainda que impossível, a democracia deve ser incessantemente buscada: "A tarefa de cada indivíduo terá que ser então a do homem que escava à procura de um tesouro que o pai, no leito de morte, lhe indicou. O tesouro, na verdade, não pode ser achado, mas o trabalho que o filho coloca na busca torna o terreno mais fértil. São apenas esses os frutos que dará a busca da democracia. [...] Não se podem iludir as desvantagens imanentes da democracia. E, contudo, no plano formal, a democracia é o mal menor" (idem, p. 428-429). Em sua busca pessoal pelo tesouro democrático, no entanto, Michels escolheria tomar um atalho, que o levaria ao totalitarismo fascista.

Pedro Floriano Ribeiro (pfribeiro@ufscar.br) é Doutor em Ciência Política pela Universidade Federal de São Carlos (Ufscar) e Professor de Ciência Política da mesma instituição.

\section{REFERÊNCIAS BIBLIOGRÁFICAS}

ALBERTONI, E. A. 1990. Doutrina da classe política e teoria das elites. Rio de Janeiro: Imago.

BOBBIO, N. 1995. Direita e esquerda: razões e significados de uma distinção política. São Paulo: UNESP

BOTTOMORE, T. B. 1974. As elites e a sociedade. Rio de Janeiro: Zahar.

BURNHAM, J. 1943. The Machiavellians: Defenders of Freedom. New York: J. Day.

CASSINELLI, C. W. 1953. The Law of Oligarchy. American Political Science Review, Washington (DC), v. 47, n. 3, p. 773-784, Sept.

COOK, P. J. 1971. Robert Michels' Political Parties in Perspective. The Journal of Politics, Cambridge (UK), v. 33, n. 3, p. p. 773-796, Aug.
COUTO, C. G. 2010. Oligarquia e processos de oligarquização: um problema institucional das organizações. Artigo apresentado no VII Encontro da Associação Brasileira de Ciência Política, realizado em Recife (Pernambuco), de 4 a 7 de agosto. Digit. Disponível em: http:/ /cepesp.fgv.br/sites/cepesp.fgv.br/files/ Couto $\% 20$ (Oligarquia).pdf. Acesso em: 15.out.2012.

DAHL, R. 1958. A Critique of the Ruling Elite Model. American Political Science Review, Washignton (DC), v. 52, n. 2, p. 463-469, June.

GRYNSZPAN, M. 1999. Ciência, politica e trajetórias sociais: uma Sociologia Histórica da teoria das elites. Rio de Janeiro: Fundação Getúlio Vargas. Disponível em: http:// cpdoc.fgv.br/producao_intelectual/arq/84.pdf. Acesso em: 15.out.2012. 
LEACH, D. 2005. The Iron Law of What Again? Conceptualizing Oligarchy Across Organizational Forms. Sociological Theory, Malden, v. 23, n. 3, p. 312-337, Sept.

LINZ, J. J. 1998. Michels y su contribución a la sociología política. Ciudad de México: Fondo de Cultura Económica.

LIPSET, S. M. 1962. Michels' Theory of Political Parties. Berkeley: University of California.

2003. Introducción. In: MICHELS, R. Los partidos políticos: un estudio sociológico de las tendencias oligárquicas de la democracia moderna. Buenos Aires: Amorrortu.

MAY, J. D. 1965. Democracy, Organization, Michels. American Political Science Review, Washington (DC), v. 59, n. 2, p. 417-429, June. Disponível em: http://people.brandeis. edu/ woll/michels.pdf. Acesso em: 15.out. 2012.

MICHELS, R. s/d. Os partidos políticos. São Paulo: Senzala.

1908. Le syndicalisme et le socialisme en Allemagne. In: LAGARDELLE, H. \& RIVIÈRE, M. (eds.). Syndicalisme et socialisme. Paris: Bibliothèque du Mouvement Socialiste.

1927. Some Reflections on the Sociological Character of Political Parties. American Political Science Review, Washington (DC), v. 21, n. 4, p. 753-772, Nov.

1968. Political Parties: A Sociological Study of the Oligarchical Tendencies of Modern Democracy. New York: Free.

1982. Sociologia dos partidos políticos. Brasília: UNB.

2001. Para uma Sociologia dos partidos políticos na democracia moderna. Lisboa: Antígona.
PANEBIANCO, A. 1995. Modelos de partido: organización y poder en los partidos políticos. Madrid: Alianza.

PRZEWORSKI, A.; STOKES, S. \& MANIN, B. 1999. Democracy, Accountability, and Representation. Cambridge (UK): Cambridge University.

RIBEIRO, P. F. 2012. A lei de ferro da oligarquia: indicadores empíricos para um teste de hipótese. Artigo apresentado no VIII Encontro da Associação Brasileira de Ciência Política, realizado em Gramado (Rio Grande do Sul), de $1^{\circ}$ a 4 de agosto. Digit.

ROTH, G. 1963. The Social Democrats in Imperial Germany: A Study in Working-Class Isolation and National Integration. Totowa: Bedminster.

SARTI, I. 1996. A utopia de Michels e a democracia partidária em perspectiva. Revista Brasileira de Ciências Sociais, São Paulo, v. 11, n. 30, p. 129-138. Disponível em: http:// www.anpocs.org.br/portal/publicacoes/ rbcs_00_30/rbcs30_12.htm. Acesso em: 15.out. 2012 .

SARTORI, G. 1960. Democrazia, burocrazia e oligarchia nei partiti. Rassegna Italiana di Sociologia, v. 1, n. 3, p. 120-123.

1994. A teoria da democracia revisitada: o debate contemporâneo. São Paulo: Ática.

SELZNICK, P. 1943. An Approach to a Theory of Bureaucracy. American Sociological Review, Chicago, v. 8, n. 1, p. 47-54, Feb. Disponível em: http://web.ku.edu/ jleemgt/ MGMT\%20916/PDF/Selznick\%201943\% 20ASR.pdf. Acesso em: 15.out.2012.

TEIXEIRA, C. P. 2000. Robert Michels: a teoria e a política da democracia. Lisboa: Universidade Técnica de Lisboa.

TUCCARI, F. 1993. I dilemmi della democrazia moderna: Max Weber e Robert Michels. Roma: Laterza. 


\section{Pedro Floriano Ribeiro}

This article discusses what the major influences on Robert Michels were in writing his book, Political Parties. I seek to move beyond the most commonly recognized sources, such as Gaetano Mosca, Vilfredo Pareto, Max Weber and Gustave Le Bon. Although Michels was not concerned with providing clear definitions of his major theoretical concepts, I attempt to reveal the essence of his reasoning, presenting the major conceptions and influences in this book and emphasizing the changes that were made from the first edition in 1911 to the second, in 1925. For these purposes, I study the 989 explanatory notes appearing in this second edition (in addition to the main text) that are revealing of the author's reasoning as well as his theoretical and empirical sources. In addition to discussing the sources that inspired the book, I also provide a genetic analysis of the work, considering some biographical information on the period prior to the book's publication and the interval between the two editions. I look at other things Michel wrote in order to get a grasp on how his thought was transformed. Finally, I point to both fragilities and contributions of his work and argue that the key to understanding his life and work resides in capturing the tense disjunctions he establishes between realism and utopia, and separating Michels the militant from Michels the political analyst.

KEYWORDS: Robert Michels; Political Parties; Iron Law of Oligarchy; Organization; Biography. 


\section{LE RÉALISME ET L'UTOPIE CHEZ ROBERT MICHELS}

\section{Pedro Floriano Ribeiro}

L'article présente et discute les principales influences théoriques et politiques de Robert Michels dans la conception de son livre La Sociologie des partis politiques, en essayant d'aller au-delà des sources les plus connues, comme Gaetano Mosca, Vilfredo Pareto, Max Weber et Gustave Le Bon. Puisque Michels ne s'est pas préoccupé à offrir des définitions claires de ses principaux concepts théoriques, on a cherché à extraire 1'essence de son raisonnement, en présentant les conceptions et les influences prédominantes dans son livre, et en soulignant les changements entre la première édition, de 1911, et la deuxième, de 1925. Pour cela, on a réalisé une étude des 989 notes explicatives de cette deuxième édition (en plus de son texte principal), qui révèlent beaucoup du raisonnement et des sources théoriques et empiriques de l'auteur. En plus de la discussion des sources explicitées dans le livre, l'article fait aussi une analyse génétique de 1'oeuvre, en vérifiant quelques faits biographiques antérieurs à sa publication, et dans la période entre les deux éditions. La transformation de la pensée de Michels est aussi remarquée en ayant recours à d'autres publications de l'auteur. L'article démontre enfin quelques faiblesses et contributions de l'oeuvre de Michels, et souligne que la clé pour que l'on comprenne la vie et l'oeuvre de l'auteur c'est d'apercevoir les séparations tendues établies entre le réalisme et l'utopie, et entre Michels autant que militant et Michels autant qu'analyste.

MOTS-CLÉS: Robert Michels; partis politiques; loi de fer de l'oligarchie; organisation; biographie. 